\title{
La tensión entre los métodos cuantitativos y cualitativos en educación: el papel de las revistas científicas
}

\author{
Editorial
}

Iván Montes-Iturrizaga

Revista

Educación y Sociedad

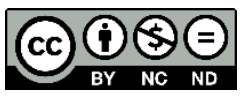

I ACEES
El enfrentamiento entre los métodos cuantitativos y cualitativos de investigación, al interior de las ciencias de la educación y las ciencias sociales, ha sido muy bien descrita por Cook y Reichardt (1989) en su célebre texto titulado Hacia la superación del enfrentamiento entre los métodos cualitativos y los cuantitativos. De ahí en adelante, estos dos autores -entre otros más- se han constituido como referentes relevantes para los ensayos que abordan esta tensión aún existente incluso en universidades de gran renombre del mundo desarrollado.

En el mencionado artículo se señala que, este debate (enfrentamiento) se debe al error de considerar que los métodos se hayan necesariamente vinculados a paradigmas filosóficos determinados. De esta manera, se asume, casi sin pensar y de manera automática, que quienes asumen una metodología cuantitativa son positivistas lógicos. Por su parte, quienes apelan a los métodos cualitativos estarían señalados o tildados como fenomenólogos, hermenéuticos u holistas.

Por lo tanto, y a la luz de lo expresado, debemos de comprender que la adhesión a un paradigma o posición filosófica determinada no necesariamente nos debe de llevar a pensar que existe un solo camino metodológico exclusivo (ya sea cuantitativo o cualitativo). En este problema también saltan a luz ciertos sentimientos y emociones con respecto a quienes usan un determinado método (Erazo, 2011). Por ejemplo, se considera prejuiciosamente a los que usan métodos cualitativos como progresistas, pro marxistas, críticos, naturalistas y hasta comprometidos con la causa ecológica y determinados partidos políticos de izquierda. También, los que optan por los métodos cuantitativos reciben con frecuencia caracterizaciones como personas 
empeñadas en cosificar la realidad humana (Montes, 2013).

Ahora bien, y en el ámbito de las Ciencias de la Educación, es fácil identificar a prominentes autores que usaron métodos cuantitativos como cualitativos sin que esto signifique necesariamente adhesión a un paradigma filosófico. Tal así, que tanto Piaget como Vygotsky realizaron estudios experimentales, observacionales y teóricos; y en cierta medida fueron los maestros de la triangulación metodológica. ¿Acaso podemos ubicar de manera simplista a estos autores en algún paradigma filosófico por el hecho de privilegiar una metodología en algunos momentos de sus vidas?, ¿El método en ellos necesariamente nos lleva a sus posiciones paradigmáticas? Esto sería, sin lugar a dudas, una pretensión en mi opinión equivocada.

Viendo las cosas de este modo, y con la intención de aportar a la superación de este impase, la experiencia nos enseña que, con frecuencia, los positivistas han investigado sobre la base de evidencia cualitativa como lo son los discursos y las conductas observables. Del mismo modo, muchos partidarios de la fenomenología han usado y usan con frecuencia métodos cuantitativos. O también, muchos investigadores usan los métodos cuantitativos para estudiar procesos y otros optar por métodos cualitativos para observar los resultados. Por último, el mundo no está solo dividido en estas dos trincheras filosóficas como para suponer de manera automática un paradigma por el método o técnica.

Estas tensiones se proyectan también, por ejemplo, a buena parte de las tesis de postgrado revisadas en países latinoamericanos -y mayormente cualitativas- donde los autores en la sección metodológica, en lugar de explicitar sus criterios de rigor, hablan del "paradigma cualitativo" de manera estereotipada (y hasta confusa). En esta misma línea no son pocos los casos en los que se añaden críticas al método cuantitativo en lugar de hablar acerca de la metodología seguida. Lo más paradójico de esto es que, con frecuencia, esta referencia al paradigma cualitativo ( $y$ a sus manifestaciones filosóficas) se queda solo como slogan en el capítulo metodológico; y desaparecen con frecuencia al momento de discutir el significado epistémico de sus hallazgos. Ante este hecho la explicitación epistemológica independientemente de la reflexión acerca de las técnicas- será necesario para comprender el proceso de construcción del conocimiento e incluso para conciliar técnicas de investigación cuantitativas y cualitativas (Meza, 2002; López-de Parra et al., 2017).

Del mismo modo, en la realidad de los pregrados en educación (y en psicología) se imponen -en la mayoría de los casos- reglamentos que ven como científico a todo lo que sea cuantitativo. Por esta razón, se desconocen los métodos y técnicas cualitativas como legítimas vías para construir conocimiento científico riguroso. En fin. Existirían prejuicios por ambos lados que configuran un panorama poco alentador para que los investigadores puedan optar libremente por una metodología a la luz de la naturaleza de sus objetos de estudio. En este sentido, la elección metodológica no puede establecerse a priori, sino más bien, supeditada siempre a lo que deseamos conocer (Montes, 2013).

En este espacio de tensión las revistas científicas están jugando un papel trascendental cuando se abren a la pluralidad metodológica; en donde sería deseable que esta apertura contemple la realización de estudios de diseño mixto donde se integren aproximaciones cuantitativas como cualitativas. Y, en este marco, se someten las contribuciones a evaluadores expertos que conozcan los estándares o normas más pertinentes para cada caso. De esta manera, se esperaría que esta amplitud de estas publicaciones periódicas, en cuanto a lo metodológico, se proyecte hacia la formación universitaria en general en la forma de cursos de metodología de la investigación, reglamentos de titulación (y grado) y en las lecturas que se asignan en las respectivas asignaturas.

En consecuencia, la Revista Educación y Sociedad tiene, como uno de sus propósitos, reflejar la basta riqueza metodológica a disposición con normas de publicación que invitan a los autores a someter sus propuestas independientemente de la vía elegida. Esto también se extiende a la amplitud teórica y epistemológica en torno a las diferentes problemáticas o campos temáticos del mundo de la educación y en su intersección con las ciencias sociales. 


\section{Referencias}

Cook, T. D., y Reichardt, Ch. S. (1989). Hacia una superación del enfrentamiento entre los métodos cualitativos y cuantitativos. Morata.

Erazo, S. (2011). Rigor científico en las prácticas de investigación cualitativa. Ciencia, Docencia y Tecnología, 23(42), 107-136. https://www.redalyc.org/articulo.oa?id=14518444004

López-de Parra, L., Polanco-Perdomo, V., y Correa-Cruz, L. (2017). Mirada de las investigaciones sobre formación investigativa en la universidad latinoamericana: estado del arte (2010-2017). Revista de Investigación Desarrollo e Innovación, 87-95. https://doi.org/10.19053/20278306.v8.n1.2017.7371

Meza, L. G. (2002). Metodología de la investigación educativa. Posibilidades de integración. Revista Comunicación, 12(1), 1-13. https://doi.org/10.18845/rc.v12i1.1223

Montes, I. (2013). La investigación en ciencias de la educación en el Perú: Aportes para el debate. Universidad La Salle. 